\title{
Injúrias em laranja 'Valência' produzida em sistemas orgânico e convencional
}

\section{Injuries in 'Valência' oranges cultivated in organic and conventional systems}

\author{
Ivan Herman Fischer ${ }^{1 *}$; Micheli Moraes Zanette ${ }^{2}$
}

\begin{abstract}
Resumo
O plantio de citros sob sistema orgânico vem aumentando anualmente, buscando atender a demanda crescente por alimentos saudáveis e produzidos de forma sustentável. Este trabalho objetivou caracterizar as injúrias de origem biótica (doenças e pragas) e abiótica (distúrbios fisiológicos e danos mecânicos) em frutos de laranja 'Valência' coletados em pomares cultivados orgânica e convencionalmente em duas localidades (Borborema e Itápolis, Estado de São Paulo), assim como em frutos de laranja 'Valência' orgânicos, comercializados na Companhia de Entrepostos e Armazéns Gerais de São Paulo (Ceagesp). Os frutos foram avaliados visualmente quanto à incidência de injúrias e submetidos a $25^{\circ} \mathrm{C}$ e $85 \%$ de umidade relativa, por 14 dias, quando avaliou-se o aumento na incidência da mancha preta dos citros (MPC) e a incidência de frutos desidratados. A MPC foi a principal doença com incidência superior a $50 \%$ nos frutos amostrados nos pomares e com um aumento médio de $17 \%$ após o armazenamento. Maior incidência de melanose foi observada nos frutos orgânicos, entretanto, para as demais doenças os resultados foram variáveis em relação ao sistema de cultivo nas localidades. Maior incidência de sintomas de fitotoxidez por defensivos foi observada nos frutos do sistema convencional. Foram observadas cinco espécies de cochonilhas, com destaque para parlatória-preta, apresentando incidências variáveis em função do sistema de cultivo nas localidades. Maiores danos por esperanças foram observados nos frutos orgânicos, enquanto os danos por bicho-furão e moscas-das-frutas foram baixos $(<2 \%)$ e semelhantes entre os sistemas de cultivo.
\end{abstract}

Palavras-chave: Citros, defensivos, mancha preta, cochonilhas

\begin{abstract}
The organic plantation of citrus comes increasing annually, searching to take care of the increasing demand for healthful foods and sustainably produced. This study aimed to characterize the injuries of biotic (diseases and pests) and abiotic origin (mechanical damage and physiological disorders) in fruits of 'Valencia' orange collected in orchards of organic and conventional crops in two locations (Borborema and Itápolis, State of Sao Paulo), as well as in organic 'Valencia' orange commercialized in the Companhia de Entrepostos e Armazéns Gerais de São Paulo (Ceagesp). Fruits were evaluated visually for the incidence of injuries and stored during 14 days at $25^{\circ} \mathrm{C}$ and $85 \%$ of UR, when were evaluated the increase in the incidence of black spot citrus (BSC) and of dehydrated fruits. The BSC was the main disease affecting more than $50 \%$ in the sampled fruits in the orchards and with an average increase of $17 \%$ after storage. The incidence of melanose was higher in organic fruits, however, for the other diseases the results varied in relation to the cropping system in the localities. The incidence of
\end{abstract}

${ }^{1}$ Pesquisador Científico IV, Agência Paulista de Tecnologia dos Agronegócios, APTA, Pólo Regional Centro-Oeste, Bauru. E-mail: ihfische@apta.sp.gov.br

${ }^{2}$ Bolsista de Iniciação Científica, FAPESP, Universidade do Sagrado Coração, Ciências Biológicas, Bauru, SP. E-mail: michelemoraeszanette@hotmail.com

* Autor para correspondência 
symptoms of pesticide phytotoxicity was higher in fruits from the conventional system. Five species of scale insects were observed, especially black parlatore, with incidences ranging depending on the farming system in the localities. Major damage by hopes were observed in organic fruits, while the damage by citrus borer and fruit fly were low $(<2 \%)$ and similar between cropping systems.

Kew words: Citrus, defensives, black spot, scales

\section{Introdução}

O Estado de São Paulo concentra 78\% da produção brasileira de laranja dos quais acima de $80 \%$ destinam-se ao processamento de suco e menos de $1 \%$ à exportação de fruta fresca (AGRIANUAL, 2010). Esta baixa exportação in natura devese às condições ambientais que fazem com que os frutos produzidos sejam mais apropriados ao processamento, e às barreiras tarifárias e restrições sanitárias, destacando a exigência de qualidade pelo mercado externo, com frutas certificadas (SPÓSITO; BASSANEZI, 2002).

Manejo inadequado da cultura no campo e durante a colheita, transporte e/ou embalagem podem provocar injúria nos frutos, definida, segundo terminologia de Zadoks (1985), como qualquer sintoma visual mensurável causado por agente biológico nocivo (praga ou doença) ou impacto mecânico. Os índices de descarte de frutos em póscolheita são geralmente reflexos dos percentuais de incidência das injúrias, uma vez que os frutos podem ser desqualificados para comercialização pela simples presença dos sintomas, independentemente de sua intensidade (GULLINO, 1994). Em adição, as injúrias mecânicas na casca do fruto favorecem a penetração de patógenos causadores de podridões compromentendo ainda mais a qualidade e a quantidade de frutos. A caracterização das injúrias visa facilitar a tomada de decisão por parte do produtor, do atacadista e do varejista quanto à necessidade de investimento em medidas de prevenção, pois só é possível decidir se a adoção de uma medida de controle será lucrativa ou não após quantificar os danos causados por determinada anomalia.

À medida que se tem questionado a aplicação de agrotóxicos, pelo problema dos seus efeitos à saúde e ao meio ambiente, vem crescendo o interesse por sistemas de cultivo agroecológico, como o orgânico, com um grande nicho de mercado a ser explorado e com normas a serem seguidas pelos agricultores certificados. O cultivo orgânico de citros vem sendo adotado em vários estados brasileiros, principalmente por pequenos produtores (CAMARGO et al., 2006). Mais de $85 \%$ da fruta cítrica orgânica tem como destino a indústria processadora, sendo a maior parte do suco exportado. Segundo Turra e Ghisi, (2004) a Europa paga quase o tripo sobre a cotação para a bebida convencional. No mercado in natura, a laranja e a banana estão entre as frutas orgânicas mais comercializadas em São Paulo (PLANETA ORGÂNICO, 2003). Entretanto, dentre as principais dificuldades encontradas pelos produtotes destacam-se a falta de experiência, de informações técnico-científicas e de insumos orgânicos (SARTORI et al., 2006).

São comuns na citicultura orgânica práticas como o uso de caldas e fertilizantes orgânicos, o monitoramento das populações de pragas e da incidência das plantas doentes (TURRA; GHISI, 2004). O uso de calda sulfocálcica viabiliza a produção de citros orgânico, devido ao sucesso no manejo das principais pragas [ácaro da leprose (Citrus leprosis virus), ácaro-da-falsaferrugem (Phyllocoptruta oleivora Ashmead), cochonilhas (Orthezia praelonga Douglas, Parlatoria ziziphus Lucas), larva minadora (Phyllocnistis citrella Stainton), etc] (PATTARO, 2003; AMBIENTEBRASIL, 2006), enquanto a aplicação da calda bordalesa visa basicamente controlar a verrugose (Elsinoe fawcetti Bitanc. \& Jenkins e E. australis Bitancourt \& Jenkins), a mancha preta (Guignardia citricarpa Kiely) e o cancro cítrico (Xanthomonas citri Vauterin et al.) 
(PANZENHAGEN et al., 2008). Menor incidência de cancro cítrico foi observada em pomar de laranja 'Valência' [Citrus sinensis (L.) Osbeck] orgânica em comparação ao pomar convencional (SARTORI et al., 2006), concordando com a teoria de Chaboussou (1987), de que adubações com nitrogênio solúvel tornam a planta mais suscetível a doenças pela presença de aminoácidos livres.

A maior micoflora ambiental encontrada em pomar de tangerineira orgânico comparado aos pomares convencionais na Espanha (PALOU et al., 2001), provavelmente se deve a intensificação da vida microbiológica do solo e ao aumento da biodiversidade relatada nos sistemas de cultivo orgânicos. Espera-se estimular a atividade microbiológica do solo e ambiental com o sistema de cultivo orgânico, procurando assim, estabelecer o controle biológico de pragas e doenças.

O presente trabalho teve por objetivo avaliar e quantificar as injúrias bióticas e abióticas em laranja 'Valência' provenientes de pomares sob cultivos orgânico e convencional, assim como as injúrias em laranja 'Valência' orgânica comercializada na Companhia de Entrepostos e Armazéns Gerais de São Paulo (Ceagesp).

\section{Material e Métodos}

Amostragens de 100 frutos de laranja 'Valência' foram realizadas mensalmente, de julho a dezembro de 2008 e 2009, em dois pomares orgânicos e em dois pomares convencionais, localizados em Borborema e Itápolis, SP. Os pomares sob cultivo orgânico a pelo menos cinco anos apresentavam em média 4.750 árvores, enquanto os pomares convencionais 12.915 árvores. Cem frutos de laranja 'Valência' orgânica foram coletados mensalmente de um atacadista na companhia de armazéns gerais de São Paulo (Ceagesp) no respectivo período, com frutos procedentes de pelo menos quatro municípios: Borborema, SP (três amostras), Domingos Martins, ES (três amostras), Gonçalves, MG (quatro amostras) e Cooperativa dos Citricultores Ecológicos do Vale do Caí, RS (Ecocitrus) (duas amostras). Os frutos amostrados nos pomares foram coletados em engradados plásticos higienizados, colhendo manualmente e aleatoriamente cinco frutos da porção mediana de 20 árvores. Os frutos orgânicos amostrados na Ceagesp foram comercializados a granel em engradados plásticos ou caixas de papelão, não passando em linha de beneficiamento e classificação em packinghose.

No manejo fitossanitário das doenças nos pomares orgânicos de Borborema e Itápolis, SP, com idades de 8 e 18 anos, respectivamente, foram empregadas, na média de 2008 e 2009, 4,0 aplicações de calda sulfocálcica/ano e 2,0 aplicação de calda bordalesa/ano no pomar de Borborema, e 3,0 aplicações de calda sulfocálcica/ano no pomar de Itápolis; enquanto nos pomares convencionais de Borborema e Itápolis, SP, com idades de 6 e 18 anos, respectivamente, foram empregadas 4,5 aplicações de oxicloreto de cobre/ano e uma aplicação de piraclostrobin, em 2009, no pomar de Borborema, e 2,5 aplicações de oxicloreto de cobre/ ano, 1,0 aplicação de trifloxystrobin, em 2008, e 1,0 aplicação de piraclostrobin e de carbendazim, em 2009, no pomar de Itápolis.

Em laboratório os frutos foram individualizados em bandejas plásticas e avaliados visualmente quanto à incidência (\%) de frutos com de injúrias bióticas (doenças e pragas) e abióticas (distúrbios fisiológicos e danos mecânicos), com base na sintomatologia caracteristica de cada injúria. Em seguida, os frutos foram submetidos a $25^{\circ} \mathrm{C}$ e $85 \%$ de umidade relativa, por 14 dias, quando avaliou-se o aumento na incidência da mancha preta dos citros (MPC) e a incidência de frutos desidratados. Como forma de monitorar o aparecimento de novas lesões de MPC identificou-se com caneta a porção do fruto com a doença (pedúnculo, superior, inferior e fundo). Em caso de dúvida, efetuou-se o isolamento direto do fitopatógeno Guignardia citricarpa em meio de cultura batata-dextrose-ágar. 
Os dados de incidência (\%) de injúrias entre os sistemas de cultivo de cada cidade foram comparados por teste não paramétrico de comparação de múltiplas proporções ao nível de 5\% de probabilidade (ZAR, 1999). Avaliaram-se separadamente os pomares de Borborema dos de Itápolis em função dos pomares de Itápolis serem mais velhos e de possíveis diferenças microclimáticas, maiores entre as cidades em relação aos pomares da mesma cidade.

\section{Resultados e Discussão}

\section{Doenças de pré-colheita}

A MPC foi a principal doença de pré-colheita nos frutos de laranja 'Valência' com incidência superior a $50 \%$ nos quatro pomares (Tabela 1 ). Após os 14 dias de armazenamento observou-se um aumento médio de $17,0 \%(5,7$ - 30,4\%) na incidência de frutos com MPC, aumento este inversamente proporcional a sua incidência inicial. A doença afeta praticamente todas as espécies de citros com importância econômica, especialmente as laranjas doces (WULANDARI et al., 2009), com relatos de incidência superior a $40 \%$ em laranjas 'Pêra', 'Lima' e 'Natal' amostradas em packinghouse paulista (FISCHER et al., 2008) e laranja 'Pêra' comercializada na Ceagesp (FISCHER et al., 2012). Em pomares cítricos orgânicos no Rio Grande do Sul estimam-se perdas de $11 \%$ na produção oriundos da queda prematura de frutos pelo ataque da MPC (PANZENHAGEN et al., 2008).

Tabela 1. Incidência $(\%)^{1}$ de doenças de pré-colheita em laranjas 'Valência' produzidas em sistema orgânico $(\mathrm{O})$ e convencional (C), armazenadas por 14 dias a $25^{\circ} \mathrm{C}$.

\begin{tabular}{lrrrrr}
\hline \multirow{2}{*}{ Doenças } & & \multicolumn{4}{c}{ Localidade $^{2}$ - Sistema de cultivo } \\
\cline { 5 - 6 } & BO & BC & IO & IC & Média \\
\hline Mancha preta (1 dia armazenamento) & $59,3 \mathrm{~b}^{3}$ & $74,6 \mathrm{a}$ & $93,5 \mathrm{a}$ & $69,5 \mathrm{~b}$ & 74,2 \\
Mancha preta (14 dias armazenamento) & $77,3 \mathrm{~b}$ & $86,1 \mathrm{a}$ & $98,8 \mathrm{a}$ & $84,8 \mathrm{~b}$ & 86,8 \\
Melanose & $42,8 \mathrm{a}$ & $4,9 \mathrm{~b}$ & $75,9 \mathrm{a}$ & $66,3 \mathrm{~b}$ & 47,5 \\
Verrugose & $44,2 \mathrm{a}$ & $16,5 \mathrm{~b}$ & $1,0 \mathrm{~b}$ & $10,8 \mathrm{a}$ & 18,1 \\
Leprose & $28,3 \mathrm{a}$ & $4,5 \mathrm{~b}$ & $1,7 \mathrm{a}$ & $3,1 \mathrm{a}$ & 9,4 \\
Fumagina & $10,3 \mathrm{a}$ & $8,3 \mathrm{a}$ & $32,5 \mathrm{a}$ & $19,3 \mathrm{~b}$ & 17,6 \\
\hline
\end{tabular}

${ }^{1}$ Média de doze amostragens mensais de 100 frutos por amostragem (jullho a dezembro de 2008 e 2009).

${ }^{2}$ Borborema $=(\mathrm{B})$ e Itápolis $=(\mathrm{I})$.

${ }^{3}$ Valores seguidos pela mesma letra minúscula na linha não diferem entre si para cada localidade, em nível de 5 \% pelo teste não paramétrico de comparação de múltiplas proporções (ZAR, 1999).

Fonte: Elaboração dos autores.

Maiores incidências de melanose (Diaporthe citri Wolf), foram observadas nos pomares orgânicos em relação aos pomares do sistema de cultivo convencional (Tabela 1). A melanose geralmente é mais severa em pomares mal conduzidos, entretanto, segundo Feichtenberger et al. (2005) a ocorrência da doença vem aumentando ano a ano no país. Em laranja 'Pêra' comercializada na Ceagesp, não foram observadas diferenças na incidência de melanose em função do sistema de cultivo convencional e orgânico (FISCHER et al., 2012). Para as demais doenças os resultados observados foram variáveis quanto ao sistema de cultivo nas duas localidades. Nos pomares de Borborema, a MPC teve maior incidência no pomar convencional, enquanto a verrugose e a leprose foram mais incidentes no pomar orgânico. Já em Itápolis, a MPC e a fumagina (Capnodium citri Berk \& Desm.) foram mais incidentes no pomar orgânico, enquanto a verrugose teve maior incidência no pomar convencional.

A curva de progresso mensal da incidência da MPC em laranjas 'Valência' produzidas em 
sistema orgânico e convencional está apresentada na Figura 1. A incidência da MCP foi superior no pomar orgânico de Itápolis em relação aos demais pomares no período avaliado, enquanto as menores incidências foram observadas no pomar orgânico de Borborema na maioria dos meses avaliados. De maneira geral, a incidência da doença nos pomares foi crescente com a maturação dos frutos, com os valores máximos atingidos no segundo trimestre (out-dez), próximo da colheita pelo produtor.
Segundo Feichtenberger et al. (2005), após a infecção o patógeno pode permanecer quiescente por até 12 meses no interior da planta hospedeira. Esse período de quiescência pode ser interrompido com a maturação do fruto ou com a ocorrência de clima favorável ao patógeno, geralmente quando a temperatura ulrapassa $21^{\circ} \mathrm{C}$. Por essa razão, os sintomas, muitas vezes, desenvolvem-se somente ao término do inverno e após a colheita dos frutos, como observado no presente trabalho.

Figura 1. Incidência mensal (\%) de mancha preta em laranjas 'Valência' produzidas em sistema orgânico (O) e convencional (C), nas cidades de Borborema (B) e Itápolis-SP (I). (média de 2008 e 2009). As barras representam o erro padrão da média de 2008 e 2009.

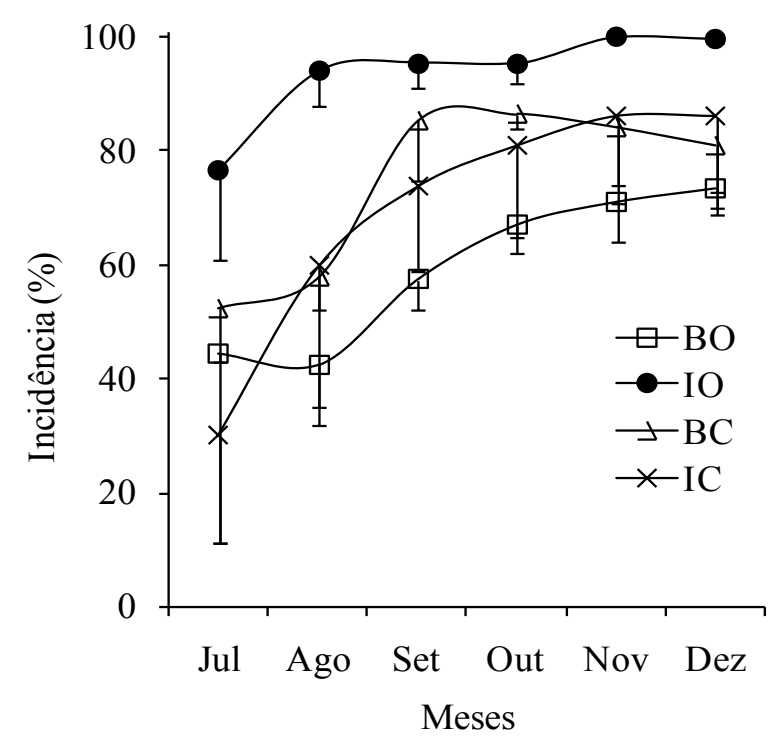

Fonte: Elaboração dos autores.

Nos frutos de laranja 'Valência' orgânica, comercializados na Ceagesp, a incidência média de mancha preta foi de $23,0 \%$, inferior em relação à observada nos frutos coletados diretamente nos pomares. Entretanto, após os 14 dias de armazenamento observou-se um aumento médio de $69,1 \%$, atingindo $38,9 \%$ de frutos sintomáticos. A doença foi constatada em todas as amostragens, entretanto, a incidência média final da MPC foi inferior a $15 \%$ nos frutos procedentes de Domingos Martins, ES e Gonçalves, MG e superior a $60 \%$ nos frutos de Borborema, SP e da Ecocitrus, RS (dados não apresentados), evidenciando diferenças significativas na incidência da doença em frutos de diferentes estados. Importância da MPC em pomares paulistas (FISCHER et al., 2008) e do Rio Grande do Sul (PANZENHAGEN et al., 2008) já havia sido relatada. As incidências médias de melanose, verrugose, leprose e fumagina foram de 35,$9 ; 11,7 ; 15,7$ e $4,0 \%$, respectivamente, valores estes, intermediários aos encontrados nos pomares 
A despeito da maior incidência da melanose ter ocorrido em laranjas 'Valência' orgânicas, a ocorrência das doenças entre os pomares foi de maneira geral variável, independente do sistema de cultivo. Muitos são os fatores, possivelmente relacionados a esta variabilidade, como diferenças no micro-clima, no manejo fitossanitário e na resistência/suscetibilidade da planta. Embora as doenças de pré-colheita não atinjam o albedo, os sintomas depreciam o valor comercial dos frutos para o mercado de fruta fresca. A MPC está incluída na lista quarentenária da Comunidade Européia (OEPP/EPPO, 2003) e caso seja detectado algum fruto com sintoma desta doença na inspeção no porto de destino todo o lote é rechaçado. Em estudo das exigências na hora da compra por parte do consumidor, do varejista e do atacadista de citros na Ceagesp, a aparência do fruto veio em primeiro lugar, sendo que os piores defeitos observados foram em ordem de importância: amassado, podridão, mancha, dano mecânico e tamanho pequeno (GUTIERREZ; ALMEIDA, 2005).

O manejo das doenças baseia-se principalmente em aplicações preventivas de defensivos, geralmente após o florescimento. Entretanto, problemas relacionados ao uso de fungicidas, como o surgimento de isolados de G. citricarpa resistentes a carbendazim (RODRIGUES et al., 2007) e restrições de ordem pública e econômica estimulam a busca de novas alternativas de controle de doenças. Para o cultivo orgânico, cuja procura por produtos é crescente uma vez que não existe tratamento padrão para o controle das doenças, há a necessidade de desenvolvimento de produtos alternativos.

\section{Injúrias abióticas}

Os resultados de injúrias abióticas nos frutos de laranja 'Valência' amostrados nos pomares orgânicos e convencionais estão expressos na Tabela 2. Maior incidência de sintomas de fitotoxidez por defensivos foi observada nos frutos do sistema convencional, uma vez que a frequência de aplicação de defensivos foi relativamente maior nestes pomares. Os danos mecânicos caracterizados por lesão não cicatrizada foram semelhantes entre os pomares, enquanto o dano mecânico de oleocelose foi variável quanto ao sistema de cultivo nas duas localidades, superior em Itápolis e inferior em Borborema, nos frutos orgânicos. Nos pomares de Itápolis, foram ainda observadas diferenças na incidência de frutos com lesão cicatrizada e desidratados.

Tabela 2. Incidência $(\%)^{1}$ de injúrias abióticas em laranjas 'Valência' produzidas em sistema orgânico (O) e convencional (C).

\begin{tabular}{lrrccc}
\hline \multirow{2}{*}{ Injúrias } & \multicolumn{7}{c}{ Localidade $^{2}$ - Sistema de cultivo } \\
\cline { 2 - 6 } & \multicolumn{1}{c}{ BO } & \multicolumn{1}{c}{ BC } & IO & IC & Média \\
\hline Oleocelose & $6,8 \mathrm{~b}^{3}$ & $12,4 \mathrm{a}$ & $6,9 \mathrm{a}$ & $4,4 \mathrm{~b}$ & 8,9 \\
Lesão cicatrizada $\left(>2 \mathrm{~cm}^{2}\right)$ & $5,2 \mathrm{a}$ & $6,5 \mathrm{a}$ & $3,3 \mathrm{a}$ & $1,5 \mathrm{~b}$ & 4,1 \\
Mancha de defensivo & $0,3 \mathrm{a}$ & $1,1 \mathrm{a}$ & $0,1 \mathrm{~b}$ & $1,5 \mathrm{a}$ & 0,8 \\
Lesão não cicatrizada & $5,3 \mathrm{a}$ & $3,4 \mathrm{a}$ & $4,8 \mathrm{a}$ & $4,3 \mathrm{a}$ & 4,4 \\
Desidratado & $11,1 \mathrm{a}$ & $12,6 \mathrm{a}$ & $6,1 \mathrm{~b}$ & $9,8 \mathrm{a}$ & 9,9 \\
\hline
\end{tabular}

${ }^{1}$ Média de doze amostragens mensais de 100 frutos por amostragem (jullho a dezembro de 2008 e 2009).

${ }^{2}$ Borborema $=(\mathrm{B})$ e Itápolis $=(\mathrm{I})$.

${ }^{3}$ Valores seguidos pela mesma letra minúscula na linha não diferem entre si para cada localidade, em nível de $5 \%$ pelo teste não paramétrico de comparação de múltiplas proporções (ZAR, 1999).

Fonte: Elaboração dos autores. 
Nos frutos de laranja 'Valência' orgânica, comercializados na Ceagesp, observou-se incidência (\%) das seguintes injúrias abióticas: oleocelose $(23,1)$, lesão cicatrizada $(6,2)$, lesão não cicatrizada $(5,0)$, amassado $(5,0)$ e desidratado $(7,6)$. De maneira geral, os danos mecânicos de oleocelose e frutos amassados foram numericamente maiores comparativamente aos frutos orgânicos amostrados nos pomares (Tabela 2), em função, possivelmente, da maior distância percorrida por caminhão, com frutos oriundos de Rio Grande do Sul, Espírito Santo e Minas Gerais (Tabela 1). Em situações em que o cliente (mercado atacadista) se localiza em distâncias acima de $1.000 \mathrm{~km}$ a partir do packinghouse, as perdas atigem a ordem de $10 \%$ em laranjas (LIMA; CAIXETA FILHO, 2004). Estas perdas de origem mecânico-patológicas se referem à abrasão proporcionada pela superfície da caixa e à falta de estabilidade da pilha, pelo fato dessas embalagens não apresentarem medidas paletizáveis, desarranjando-se durante o percurso, principalmente em estradas com péssimas condições. Destaca-se também a necessidade de cuidados na operação de colheita, evitando-se a queda dos frutos no chão que provoca a oleocelose e pode contaminar os frutos com microorganismos. Preconiza-se acondicionar os frutos com cuidado na sacola ou saco-caixa e não realizar a colheita em dias úmidos ou nas primeiras horas da manhã, quando os frutos estão túrgidos e mais suscetíveis a oleocelose. Isto é muito importante para o caso da lima ácida Tahiti (C. latifolia Tan.), cuja casca é mais sensível que as demais espécies de citros (POZZAN; TRIBONI, 2005).
Pragas

Foram observadas cinco espécies de cochonilhas, com destaque para parlatória-preta, com 58,4\% de incidência, na média dos pomares, seguida pela escama-vírgula vírgula (Cornuaspis beckii Newmann e Insulaspis gloverii Packard) (30,2\%) e pardinha (Selenaspidus articulatus Morgan) $(13,8 \%)$ (Tabela 3). A cochonilha parlatóriapreta caracteriza-se por ser polífaga e ocorrer na maioria dos pomares cítricos do mundo, sendo frequentemente associada aos frutos cítricos (GALLO et al., 2002). Elevada ocorrência de cochonilhas, com incidências superiores a $20 \%$, também foram observados por Fischer (2007) em frutos amostrados em packinghouse e na CeagespSP. Em menor incidência média foram observadas as cochonilhas cabeça-de-prego (Chrysomphalus aonidum Linnaeus) e escama-lixa (Mycetaspis personata Comstock). Entretanto, a incidência das cochonilhas foi divergente em função do sistema de cultivo nas duas localidades, a exemplo das três cohonilhas mais incidentes, com maior ocorrência no pomar orgânico de Borborema e no pomar convencional de Itápolis. Já em laranja 'Pêra' comercializada na Ceagesp, maiores incidências das cochonilhas cabeça-de-prego, pardinha, escama-vírgula e parlatória-preta foram observados nos frutos orgânicos, enquanto maior incidência da cochonilha escama-lixa foi observada nos frutos do sistema convencional (FISCHER et al., 2012). 
Tabela 3. Incidência (\%) ${ }^{1}$ de insetos pragas em laranjas 'Valência' produzidas em sistema orgânico (O) e convencional (C).

\begin{tabular}{lrrrrc}
\hline \multirow{2}{*}{ Pragas } & \multicolumn{5}{c}{ Procedências $^{2}-$ Sistema de cultivo } \\
\cline { 2 - 5 } & BO & BC & IO & IC & Média \\
\hline Parlatória-preta & $67,0 \mathrm{a}$ & $25,8 \mathrm{~b}$ & $66,2 \mathrm{~b}$ & $74,8 \mathrm{a}$ & 58,4 \\
Escama-vírgula & $37,4 \mathrm{a}$ & $9,6 \mathrm{~b}$ & $28,2 \mathrm{~b}$ & $45,5 \mathrm{a}$ & 30,2 \\
Pardinha & $14,1 \mathrm{a}$ & $14,0 \mathrm{a}$ & $6,3 \mathrm{~b}$ & $21,0 \mathrm{a}$ & 13,8 \\
Cabeça-de-prego & $4,5 \mathrm{a}^{3}$ & $3,1 \mathrm{a}$ & $7,3 \mathrm{a}$ & $3,3 \mathrm{~b}$ & 4,5 \\
Escama-lixa & $2,2 \mathrm{a}$ & $3,5 \mathrm{a}$ & $8,3 \mathrm{a}$ & $1,7 \mathrm{~b}$ & 3,9 \\
Bicho-furão & $1,6 \mathrm{a}$ & $0,7 \mathrm{a}$ & $0,7 \mathrm{a}$ & $1,8 \mathrm{a}$ & 1,2 \\
Moscas-das-frutas & $1,1 \mathrm{a}$ & $0,6 \mathrm{a}$ & $0,9 \mathrm{a}$ & $1,5 \mathrm{a}$ & 1,0 \\
Esperanças & $1,8 \mathrm{~b}$ & $11,0 \mathrm{a}$ & $4,9 \mathrm{~b}$ & $15,0 \mathrm{a}$ & 8,2 \\
Falsa-ferrugem & $10,1 \mathrm{a}$ & $1,3 \mathrm{~b}$ & $0,1 \mathrm{~b}$ & $4,8 \mathrm{a}$ & 4,1 \\
Tripes & $8,4 \mathrm{a}$ & $3,6 \mathrm{~b}$ & $3,8 \mathrm{a}$ & $3,5 \mathrm{a}$ & 4,8 \\
\hline
\end{tabular}

${ }^{1}$ Média de doze amostragens mensais de 100 frutos por amostragem (julho a dezembro de 2008 e 2009).

${ }^{2}$ Borborema $=(\mathrm{B})$ e Itápolis $=(\mathrm{I})$.

${ }^{3}$ Valores seguidos pela mesma letra minúscula na linha não diferem entre si para cada localidade, em nível de 5 \% pelo teste não paramétrico de comparação de múltiplas proporções (ZAR, 1999).

Fonte: Elaboração dos autores.

Maiores incidências dos danos por esperanças foram observadas nos frutos orgânicos (Tabela 3), enquanto os danos por bicho-furão (Ecdytolopha aurantiana Lima) e moscas-das-frutas (Ceratitis capitada Wied., Anastrepha spp. e Neosilba spp.) foram semelhantes entre os sistemas de cultivo. Incidências variáveis em relação aos sistemas de cultivo nas duas localidades também foram observadas para os danos do ácaro-da-falsa-ferrugem e tripes (Heliothrips haemorrhoidalis Bouché e Frankliniella insularis Franklin). Diferentemente da laranja 'Valência', em laranja 'Pêra' comercializada na Ceagesp, maiores incidências dos danos por moscas-das-frutas e ácaro da falsa-ferrugem foram observados nos frutos orgânicos, enquanto maiores incidências dos danos de esperanças e tripes foram observados nos frutos do sistema convencional (FISCHER et al., 2012).

Nos frutos de laranja 'Valência' orgânica, comercializados na Ceagesp, a incidência média das cochonilhas parlatória-preta, escama-vírgula, pardinha, cabeça-de-prego e escama-lixa foi de 22,$2 ; 20,8 ; 14,0 ; 2,6$ e 1,9\%, respectivamente. Frutos com sintomas de ataque de bicho-furão e moscas-das-frutas foram de $0,4 \%$. Também foram observados danos de esperanças $(4,9 \%)$, do ácaroda-falsa-ferrugem $(10,8 \%)$ e de tripes $(5,5 \%)$. Comparativamente aos pomares estudados de laranja 'Valência' orgânica os resultados foram equiparáveis, exceto pela menor incidência das cochonilhas parlatória-preta, escama-vírgula e cabeça-de-prego (Tabela 3).

As cochonilhas encontradas nos frutos cítricos possuem carapaça e estão entre as que mais ocorrem nos pomares brasileiros, sendo que as três espécies mais frequentes ocorrem durante o ano todo, apresentando picos nos meses mais quentes e úmidos (PINTO, 1995; PARRA et al., 2005). As cochonilhas promovem a sucção da seiva e injeção de toxinas, promovendo, sob ataques intensos, a queda prematura e deformação de frutos. No local da punctura, manchas verdes permanecem após o beneficiamento, depreciando comercialmente o fruto. A excreção de um líquido açucarado (honeydew) pelas cochonilhas favorece o desenvolvimento da fumagina que recobre o fruto (PARRA et al., 2005). A menor incidência de fumagina nas laranjas dos pomares de Borborema (Tabela 1), possivelmente está diretamente associada a menor incidência das cochonilhas, uma vez que 
as maiores incidências para cada cochonilha foram observadas nos pomares de Itápolis (Tabela 3).

As moscas-das-frutas são consideradas pragas "chaves" dos citros, devido ao dano que causam, exigindo constante monitoramento populacional e intervenções oportunas para reduzir as suas populações nos pomares. O problema são as larvas, que se alimentam da polpa e levam ao apodrecimento e queda dos frutos. No Brasil, as espécies de moscasdas-frutas de importância econômica englobam-se nos gêneros Anastrepha e Ceratitis. Estima-se que os danos ocasionados por $C$. capitata varia de 1,2 a 4,1 toneladas de frutos por hectare (PAIVA, 2004). Estimativas de danos por Anastrepha fraterculus Wiedemann chegam a $20 \%$ do total da produção e $6,9 \%$ em média, em pomares orgânicos do Rio Grande do Sul (PANZENHAGEN et al., 2008). O ensacamento de frutos foi a melhor alternativa na diminuição da intensidade dos danos por moscasdas-frutas em pomares cítricos orgânicos, enquanto o uso de calda sulfocálcica e soro de leite foram pouco eficientes (SILVA et al., 2007).

O bicho-furão também é considerado uma das principais pragas da citricultura, com danos estimados em algumas regiões do Estado de São Paulo de 0,5 a 1,5 caixa de frutos por árvore, sob alta infestação (PARRA et al., 2005). Através do monitoramento de E. aurantiana por meio de armadilhas com feromônio sexual, em 553 áreas localizadas em 17 fazendas paulistas, constatouse maior influência sobre a flutuação populacional do bicho-furão pelo tipo de solo, seguido pela temperatura mensal média do local, variedade de citros, idade das plantas e uso de agroquímicos (REIS; PARRA; BENTO, 2005).

Em pós-colheita, a incidência de moscas-dasfrutas e do bicho-furão foi relativamente baixa, inferior a 2,0\% dos frutos, semelhante ao observado por Fischer (2007). Segundo as recomendações das Normas de Classificação de Citros de Mesa (CEAGESP, 2011) que classifica os frutos em três categorias (Extra, I e II) com base em defeitos, os frutos amostrados na Ceagesp e nos pomares enquadram-se nas categorias I e II, com limites (\%) de podridões (defeito muito grave) de 1 e $3 \%$ dos frutos, respectivamente, considerando a soma dos danos por moscas-das-frutas e bicho-furão (Tabela 3).

\section{Conclusões}

Com base nos resultados obtidos pode-se concluir:

-A mancha preta é a principal doença nos frutos de laranja 'Valência', apresentando incidência variável em função do sistema de cultivo orgânico e convencional e da localidade intra e interestadual;

-Frutos produzidos no sistema convencional apresentam maior incidência de sintomas de fitotoxidez por defensivos, decorrente da maior intensidade de aplicação de defensivos;

-A incidência de cochonilhas é elevada nos frutos cítricos, independente do sistema de cultivo.

\section{Agradecimentos}

Os autores agradecem à Fundação de Amparo à Pesquisa do Estado de São Paulo (FAPESP) pelo apoio financeiro concedido ao projeto de pesquisa (Proc. 2007/08519-4) e à Profa. Lílian Amorim da ESALQ/USP por informações importantes.

\section{Referências}

ANUÁRIO DA AGRICULTURA BRASILEIRA AGRIANUAL. Laranja. São Paulo: Instituto FNP, 2010. p. 271-289.

AMBIENTEBRASIL. Principais produtos orgânicos produzidos no Brasil. [S.1.: s.n.], 2006.

CAMARGO, A. M. M. P.; CASER, D. V.; CAMARGO FILHO, W. P.; CAMARGO, F. P.; VOELHO, P. J. Área cultivada com agricultura orgânica no estado de São Paulo, 2004. Informações econômicas, São Paulo, v. 36, n. 3, p. 33-62, 2006. 
COMPANHIA DE ENTREPOSTOS E ARMAZÉNS GERAIS DE SÃO PAULO - CEAGESP. Programa brasileiro para modernização da horticultura. Normas de classificação de citros de mesa. Centro de qualidade em horticultura. São Paulo: CQH/CEAGESP, 2011. 12 p.

CHABOUSSOU, F. Plantas doentes pelo uso de agrotóxicos: a teoria da trofobiose. Porto Alegre: L \& PM, 1987. $256 \mathrm{p}$.

FEICHTENBERGER, E.; BASSANEZI, R. B.; SPÓSITO, M. B.; BELASQUE JUNIOR, J. Doenças dos citros (Citrus spp.). In: KIMATI, H.; AMORIM, L.; REZENDE, J. M.; BERGAMIN FILHO, A.; CAMARGO, L. E. A. (Ed.). Manual de Fitopatologia: doenças das plantas cultivadas. 4. ed. São Paulo. Ceres, 2005. v. 2, p. 239-269.

FISCHER, I. H. Doenças pós-colheita em citros e caracterização da população fúngica em packinghouses e na Ceagesp-SP. 2007. Tese (Doutorado em Agronomia) - Escola Superior de Agricultura Luiz de Queiroz. Universidade de São Paulo, Piracicaba.

FISCHER, I. H.; TOFFANO, L.; LOURENÇO, S. A.; SPÓSITO, M. B.; AMORIM, L. Incidência de mancha preta em frutos cítricos em diferentes etapas de beneficiamento em packinghouses e na Ceagesp de São Paulo. Tropical Plant Pathology, Lavras, v. 33, n. 4, p. 326-330, 2008

FISCHER, I. H.; FILETI, M. S.; PALHARINI, M. C. A.; AMORIM, L. Injúrias em laranja Pêra produzida em sistema orgânico e convencional comercializada na Ceagesp. Citrus Research \& Technology, Codeirópolis, v. 33, n. 1, p. 39-47, 2012.

GALLO, D.; NAKANO, O.; SILVEIRA-NETO, S.; CARVALHO, R. P. L.; DEBATISTA, G. C.; BERTIFILHO, E.; PARRA, J. R. P.; ZUCCHI, R. A.; ALVES, S. B.; VENDRAMIM, J. D. Manual de entomologia agrícola. Piracicaba: FEALQ, 2002. 920 p.

GULLINO, M. L. Lotta biologica a funghi agenti di marciumi della frutta in post-raccolta. Informatore Fitopatogico, Bologna, v. 4, n. 1, p. 5-13, 1994.

GUTIERREZ, A. S. D.; ALMEIDA, G. V. B. Beneficiamento e comercialização de frutos in natura. In: MATTOS JUNIOR, D.; DE NEGRI; J. D.; PIO, R. M.; POMPEU JUNIOR, J. (Ed.). Citros. Campinas: Instituto Agronômico e Fundag, 2005. cap. 27, p. 823-836.

LIMA, L. M.; CAIXETA FILHO, J. V. Análise da viabilidade econômica de embalagens para laranja de mesa no estado de São Paulo (Compact disc). In: CONGRESSO BRASILEIRO DE ECONOMIA E
SOCIOLOGIA RURAL, 42., 2004, Cuiabá. Anais... Cuiabá: Sociedade Brasileira de Economia e Sociologia Rural, 2004. p. 1-17.

ORGANISATION EUROPÉENNE ET MÉDITERRANÉENNE POUR LA PROTECTION DES PLANTES/EUROPEAN AND MEDITERRANEAN PLANT PROTECTION ORGANIZATION - OEPP/ EPPO. Diagnostic protocols for regulated pests. Guignardia citricarpa. Bulletin of the OEPP/EPPO, Paris, v. 33, p. 271-280, 2003.

PAIVA, P. E. B. Moscas-das-frutas em citros: densidade de armadilhas para monitoramento, efeito de $\mathrm{pH}$ na atração e determinação do nível de controle. 2004. Dissertação (Mestrado em Agronomia) - Escola Superior de Agricultura Luiz de Queiroz. Universidade de São Paulo, Piracicaba.

PALOU, L.; USALL, J.; PONS, J.; CERDÀ, M. C.; VIÑAS, I. Micoflora em centrales citrícolas de Tarragona. Revista Investigación Agraria: Production Protección Vegetal, Madrid, v. 16, n. 3, p. 447-462, 2001.

PANZENHAGEN, N. V.; KOLLER, O. C.; VAQUIL, P. D.; SOUZA, P. V. D.; SOGLIO, F. K. D. Aspectos técnico-ambientais da produção orgânica na região citrícola do Vale do Rio Caí, RS. Ciência Rural, Santa Maria, v. 38, n. 1, p. 90-95, 2008.

PARRA, J. R. P.; LOPES, J. R. S.; ZUCCHI, R. A.; GUEDES, J. V. C. Biologia de insetos-praga e vetores. In: MATTOS JUNIOR, D.; DE NEGRI, J. D.; PIO, R. M.; POMPEU JUNIOR, J. (Ed.). Citros. Campinas: Instituto Agronômico e Fundag, 2005. cap. 22, p. 657-683.

PATTARO, F. C. Calda sulfocálcica no agrossistema citrícola. 2003. Dissertação (Mestrado em Sanidade Vegetal) - Faculdade de Agronomia. Universidade Estadual Paulusta Júlio Mesquita Filho, Jaboticabal.

PINTO, A. DE S. Distribuição e flutuação populacional da cochonilha Selenaspidus articulatus (Morgan) (Hemiptera: Diaspididade) em citros e seus inimigos naturais em Taquaritinga. 1995. Dissertação (Mestrado em Sanidade Vegetal) - Faculdade de Agronomia. Universidade Estadual Paulusta Júlio Mesquita Filho, Jaboticabal.

PLANETA ORGÂNICO. Os supermercados $e$ o consumo de frutas, legumes, verduras, (FLV) orgânicos certificados. [S.1.: s.n.], 2003.

POZZAN, M.; TRIBONI, H. R. Colheita e qualidade do fruto. In: MATTOS JUNIOR, D.; DE NEGRI, J. D.; PIO, R. M.; POMPEU JUNIOR, J. (Ed.). Citros. Campinas: Instituto Agronômico e Fundag, 2005. cap. 26, p. 799822. 
REIS, R. J.; PARRA, J. R. P.; BENTO, J. M. S. Desenvolvimento de um modelo para previsão de ocorrência do bicho-furão-dos-citros, Ecdytolopha aurantiana (Lima) (Lepidoptera: Tortricidae. Neotropical Entomology, Londrina, v. 34, n. 4, p. 627-637, 2005.

RODRIGUES, M. B. C.; ANDREOTE, F. D.; SPÓSITO, M. B.; AGUILLAR-VILDOSO, C. I.; ARAÚJO, W. L.; PIZZIRANI-KLEINER, A. A. Resistência a benzimidázois por Guignardia citricarpa. Pesquisa Agropecuária Brasileira, Brasília, v. 42, n. 3, p. 323-327, 2007.

SARTORI, I. A.; PANZENHAGEN, N. V.; SOARES, D. N.; DAL'SOGLIO, F. K.; MANZETE, F. KOLLER, O. C. Sistemas de cultivo orgânico e convencional em laranjas 'Valência'. Revista Brasileira de Agroecologia, Porto Alegre, v. 1, n. 1, p. 207-211, 2006.

SILVA, F. F.; MEIRELLES, R. N.; SOGLIO, F. K. D.; REDAELLI, L. R. Comparação de métodos de controle de moscas-das-frutas (Diptera: Tephritidae) na produção orgânica de citros. Revista da FZVA, Uruguaiania, v. 14, n. 1, p. 36-52, 2007.

SPÓSITO, M. B.; BASSANEZI, R. B. Problemas sanitários na pós-colheita para a exportação de frutas cítricas e métodos de controle. In: SIMPÓSIO DE CONTROLE DE DOENÇAS DE PLANTAS: PATOLOGIA PÓS-COLHEITA DE FRUTOS E HORTALIÇAS, 2., 2002, Lavras. Anais... Lavras: UFLA/FAEPE, 2002. p. 79-83.

TURRA, C.; GHISI, F. A. Laranja orgânica no Brasil: produção, mercado e tendências (Compact disc). In: CONGRESSO BRASILEIRO DE ECONOMIA E SOCIOLOGIA RURAL, 42., 2004, Cuiabá. Anais... Cuiabá: Sociedade Brasileira de Economia e Sociologia Rural, 2004. p. 1-12.

WULANDARI, N. F.; TO-ANUN, C.; HYDE, K. D.; DUONG, L. M.; De GRUYTER, J.; MEFFERT, J. P.; GROENEWALD, J. Z.; CROUS, P. W. Pyllosticta citriasiana sp., nov. the cause of citrus tan spot of Citrus maxima in Asia. Fungal Diversity, Indonesia, v. 34, n. 1, p. 23-39, 2009.

ZADOKS, J. C. On the conceptual basis of crop loss assessment: the threshold theory. Annual Review of Phytopathology, Palo Alto, v. 23, n. 1, p. 455-473, 1985.

ZAR, J. H. Biostatistical analyis. New Jersey: PrenticeHall, 1999. 663 p. 
